\title{
A digital platform as a facilitator for assessing innovation potential and creating business models: a case study from the i3 project
}

\author{
Francesco BELLINI \\ Eurokleis srl/ International Telematic University UNINETTUNO, Roma, Italy \\ francesco.bellini@eurokleis.com \\ Iana DULSKAIA \\ Eurokleis srl / University La Sapienza - Dept. of Management, Roma, Italy \\ iana.dulskaia@eurokleis.com
}

\begin{abstract}
Many ideas flow into the innovation funnel but only 1 out 3000 becomes a successful new product. There are many variables that interact in this complex process and investors decisions are often based on experience and feeling rather than a comprehensive evaluation of the social, economic and technological factors. The innovation potential, the innovator capability, the accessibility of the technology as well as the social acceptance and the chosen business model are the some of the critical factors of a successful innovation strategy. In the broad sense, a business model is the approach of doing business through which a company can sustain itself and generate profits in the long term. Digital platforms can help manage and facilitate the complexity of value propositions and provide an immediate feedback to the entrepreneur. Creating value is necessary, but not sufficient, for an organization to profit from its business model. It is important to see the whole picture of the business that is why the business models are so important for a good start of the business. However, innovation assessment and business model development sometimes are not an easy task and ICT can make this process easier. Then, the aim of this paper is to explore the role of digital platforms as facilitators for the techno-socio-economic impact assessment and the development of sustainable business models through the analysis of a case study from the EU Horizon 2020 "i3 project".
\end{abstract}

Keywords: innovation, impact, business model, digital platforms, business plan.

\section{Introduction}

Research \& Innovation projects are developed by technology researcher that often forget to take the needed care of the business implications of their achievements. At the same time the research funding bodies (i.e. the European Commission for the Horizon 2020 Framework Programme) are increasingly concerned regarding the actual return and the accountability of the research investment considering that the money comes from the tax payers' contribution. Therefore, the European Commission launched some calls for supporting action projects aimed at helping vertical initiatives to maximize their innovation impact and reduce the timing from the completion of the R\&I activities to the market exploitation.

During the project (http://i3project.eu/) a specific methodology and an online tool were developed in order to help researchers working in the media technologies (namely Social Media and Convergence sector) to become entrepreneurs by helping them to evaluate their innovation and build their own business model with the aim of presenting it to investors. 


\section{Literature review}

\section{An Introduction to Social Media and Convergence Sector}

The term convergence in the digital and creative industries domain is said to denote the technical convergence of communication networks and protocols. Media convergence is thus a process that is not a displacement of so-called old media, but rather the interaction between different media forms and platforms (Jenkins, 2006). It should be regarded as cooperation and collaboration between previously unconnected forms and platforms of media. This process facilitates the further convergence of markets, industries and service provisions. In technical terms, it becomes easier to repurpose, or, modify intellectual property for multiple media and create new connections between distinct media 'spaces' or associated 'experiences'.

Social media is indispensable to convergence. Social media is a widely used umbrella term that refers to the set of tools, applications, and services that enable people to interact with others using network technologies such as personal computers, smart-phones, tablets, and network capable televisions. Facilitated by user friendly and attractively priced (or free) software technologies, social media sites on the Internet are "all forms of digital culture, networked in technology and collaborative in principle" (Uricchio, 2004). Social media also describes a convergence of production, distribution, and consumption practices, a blending of user creativity, collaboration, and sharing. It is thus said to support democratization of knowledge and information associated with a shift from mere consumers to content producers.

Corporations constantly look for new ways of monetizing online creativity and sociality (selling virtual products, subscriptions, advertising, (meta) data etc.) and research veers between viewing monetizing strategies as a static exploitation model and as dynamic facilitator in the process of shaping sociality and creativity. In this context, associated issues such as ownership structures are very relevant to keep in mind and can underpin various examinations of the i3 researchers.

\section{Scope and Challenges for i3 Impact assessment}

The aim of the i3 self-assessment methodology - that is made operational through a specific software tool - is to enable Social Media and Convergence projects to evaluate the potential impact of the innovations developed during their lifetime. The impact is measured not only in terms of socio-economic benefits for participating partners and the society, but also and mainly in terms of capability of participating projects to act as real innovators and build sustainable business models. The self-assessment activity is thus also preparatory to subsequent phases of the $\mathrm{i} 3$ project where investors attraction and acceleration of business initiatives is addressed.

It is important to mention that the i3 methodology was developed starting from previous European project experiences in the field of impact assessment. Notably, these include SEQUOIA (Passani et al., 2014), ERINA+ (Bellini et al., 2012), MAXICULTURE (Bellini et al., 2012) and IA4SI (Passani et al., 2016). The methodologies developed for these projects have been tuned in accordance with the EC guidelines. They thus represent the foundation of the overall i3 framework and offer decisive lessons learned, which are being incorporated in the i3 tool as described in the following paragraphs. While supported by previous experiences, i3's indicators and variables are tailored to the Convergence and Social Media domain. 


\section{The impact value chain}

According to the International Association for Impact Assessment (IAIA), impact is defined as "the difference between what would happen with the action and what would happen without it ${ }^{1}$ ". In line with this, the impact assessment strategy for i3 will allow estimating the impact of each project responding to three main questions:

- What is the difference that a project makes?

- Why is the project relevant and for whom?

- How much difference does the project make?

Referring to literature (European Commission, 2012), the first issue that needs to be taken into account is the time frame in which the impact is observable. Following the EC (2012), only after two to five years after the end of the project it is possible to measure its impact. i3 will analyse and will be mainly focused on expected impacts.

The analysis of expected impacts will be conducted in line with the strategy developed by Ebrahim and Rangan (2010) in the value chain approach, also called logic chain.

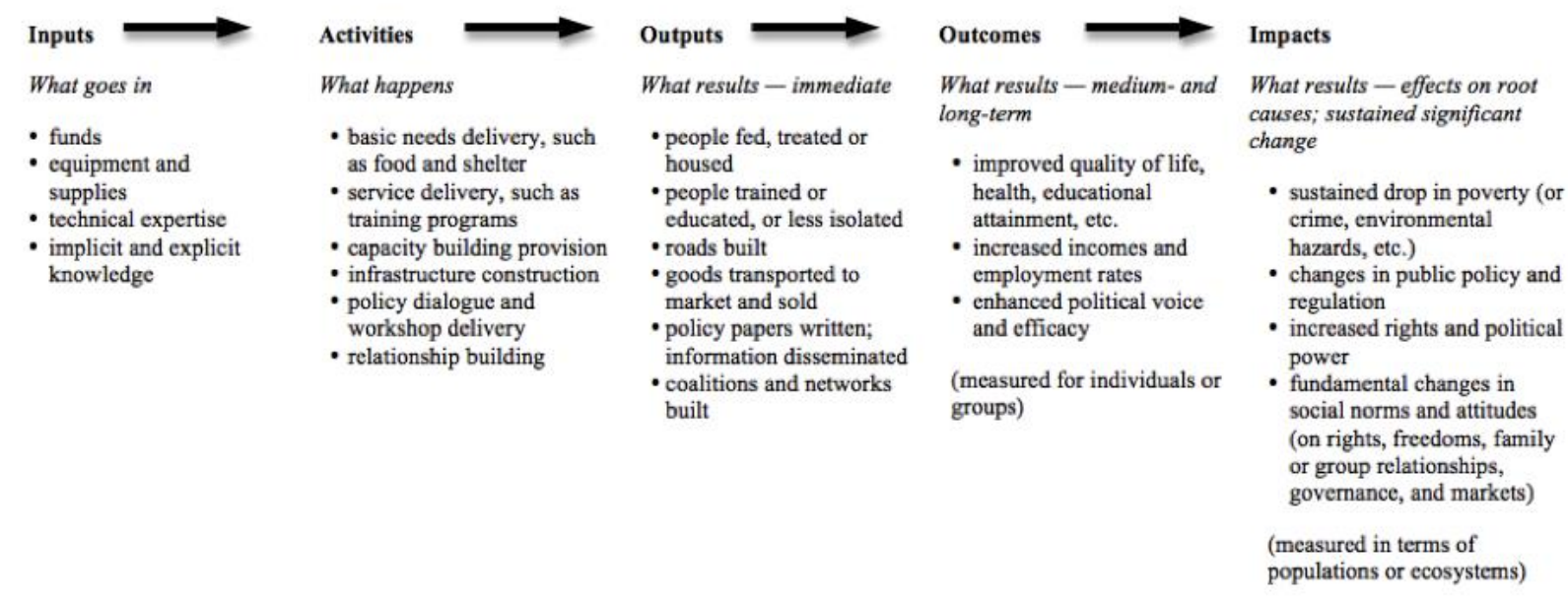

Figure 1. Logic model

Source: Ebrahim and Rangan (2010, p. 49).

Adapting from Epstein and McFarlan (2011) and looking in detail to the logic model it is possible to identify 5 clusters that need to be analysed carefully to derive a measure of impact: inputs, activities, outputs, outcomes and impacts.

Inputs: the key tangibles (monetary) and intangibles (non-monetary) investments made in a project. Investment can be several and variegated such as: funds, equipment, technical expertise, but can also be related to knowledge. This preliminary analysis will be conducted by i3 relevant inputs according to all projects.

Activities: specific programs or actions that the analysed project is undertaking. In the case of the projects observed within i3 this will be the development of technologies, piloting activities performed, involvement of stakeholders, workshops etc.

Outputs: tangible and intangible products and services that are the result of activities. Describing outputs means describing observable results of a project such as the

\footnotetext{
${ }^{1}$ Available at http://www.iaia.org/publicdocuments/special-publications/What\%20is\%20lA_web.pdf
} 
number of published scientific papers, the number of pilots implemented, the number of developed policy recommendations, etc. They need to be constantly monitored during the project lifecycle.

Outcomes: specific changes in behaviours and affected by the delivery of services and products created by the projects. Analysing outcomes means analysing the short-time effect the project asserts on its stakeholders. The main difference between outcomes and impact is the time frame in which they can be observed. The i3 methodology develops a set of variables that merge outcomes and expected impact assuring the possibility to map both outcomes and expected impacts.

Impacts: benefits in the social media convergence domain and for the society as a whole as a result of the project outcomes. Impacts are the difference made by an activity after the outputs interact with society and the economy.

i3 will follow this approach in order to finally derive project expected impacts analysing the complete value chain.

\section{Main Methodological Approaches}

There is a great variety of evaluation techniques to perform an impact assessment. Each differs in level of detail, range of considered stakeholders, characteristics of required data and final aim.

From the Evalsed manual (European Commission, 2012), we selected two of the four main methodologies that are currently used for socio-economic impact assessments:

Cost-Benefit Analysis (CBA): is aimed at evaluating the net economic impact of a public project involving public investments. A CBA is used to determine if project results are desirable and produce an impact on the society and economy by evaluating quantitatively monetary values. CBA considers externalities and shadow prices, allowing also the consideration of market distortions. Usually, a CBA is used in ex-ante evaluations for the selection of an investment of a project or in the ex-post evaluation in order to assess the economic impact of project activities. In i3, this approach is used for analysing the economic impact of Social media project.

Multi-Criteria Analysis (MCA): is used to evaluate non-monetary values of a project and to compare and aggregate heterogeneous values (tangibles and intangibles, monetary and non-monetary). A MCA combines different decision-making techniques for assessing different impacts of the same project. It is aimed at identifying the opinion expressed by all stakeholders and end-users of a project in order to formulate recommendations and to identify best practices. The MCA is used for evaluating social, political, environmental and economic impacts that cannot be expressed in monetary terms (Mendoza and Macoun, 1999; Mendoza and Martin, 2006).

The i3 methodology is grounded on the CBA and on the Multi-Criteria analysis MCA in order to be able to describe impact measurable in monetary terms and impact not measurable in monetary terms.

Given the aims of the i3 project, the self-assessment methodology also needs to include aspects related to the capability of building sustainable business models and the innovation capacity of projects. The i3 approach then includes and adapts the features the Business Model Canvas (BMC) and the Innovation Radar IR).

The Business Models Canvas (Osterwalder and Pigneur, 2010) was mainly deployed in order to shape the economic section of the assessment. It investigates the structure of the 
building blocks (customers, value proposition, resources, processes, business plan) of a sustainable business model.

The Innovation Radar (De Prato et al., 2015) supports innovators in EU-funded projects by suggesting a range of targeted actions to assist them in reaching their potential in the market. It is an initiative that involves:

- Assessing the maturity of innovations developed within the FP7 and H2020 projects and identifying high potential innovators and innovations (using a model developed by JRC-IPTS)

- Providing guidance during the project duration in terms of the most appropriate steps to reach the market

- Supporting innovators through EU (and non-EU) funded entrepreneurship initiatives to cover specific needs concerning networking, access to finance, Intellectual Property Rights, etc.

\section{i3 Methodology}

This paragraph describes the i3 indices, indicators and variables. They will be used for describing and quantifying outputs, outcomes and impacts of Convergence and Social Media projects. It is important to remember that the methodology is modular so that each project is able to personalize it by defining those parts that are more relevant for its activities. The indices described here correspond to the operational definition of the expected impact of Convergence and Social Media projects.

The assessment model is built by using indicators proposed from the above mentioned techniques and adapting them to the i3 operational context: the result is a framework that adopts 3 synthetic indices related to specific areas of impact and related sub categories, visualised in following figure. Each index is composed of sub-indices corresponding to specific subcategories; for example, the synthetic index Economic impact is composed of 7 sub-indices.

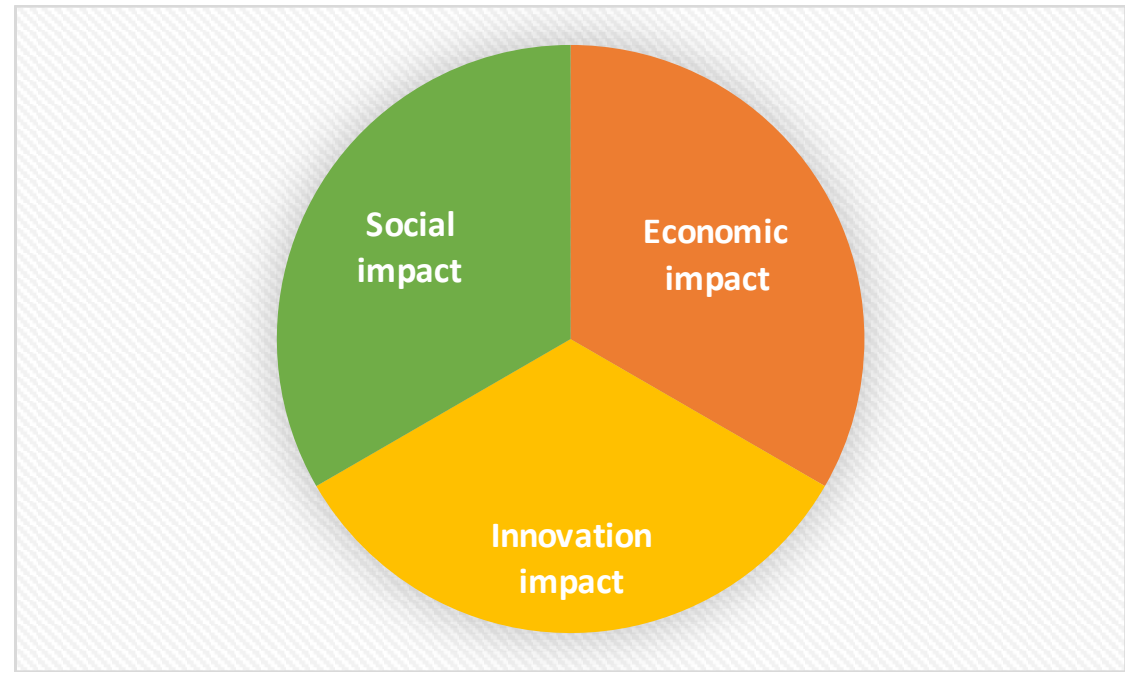

Figure 2. i3 impact areas

\section{Economic impact}

Source: Authors' own illustration. 
This area of impact and associated indices consider all relevant economic results that projects develop in their lifetime. i3 provides an assessment of Convergence and Social Media projects by focusing on their economic, financial, organisational, generated value impacts at the level of projects partners and their stakeholders (micro level). The assessment is conceived in order to help projects (and their partners) to identify a Value Proposition model and Business Model Canvas parameters that will be further discussed with the i3 team during the project support activities.

Customer segmentation: helps to better define the different groups of people or organisations that the project outputs (good/services) aims to reach and serve. Customers comprise the heart of any business model. In order to better satisfy customers, a company may group them into distinct segments with common needs, common behaviour or other attributes. This subcategory should help projects to answer a questions "For whom are we creating value?", "Who are our most important customers?"

Value propositions: aims at helping projects to understand how goods and services can create for their customer segment. The value proposition is the reason why customers prefer one company to another. Value proposition may be innovative and represent a new offer or can already exist on the market but have an added features and attributes. This indicator will help the projects to answer the following questions: "What value do we deliver to the customer?", "Which one of our customers' problems we are trying to solve?", "Which customer needs are we satisfying?"

Channels: allows projects to understand and choose a better way of communication and achievement of their customer segments for delivering a value proposition. Channels serve several functions, including 1. raising awareness among customers about a company's products and services; 2. Helping customers evaluate value propulsion; 3. Allowing customers to purchase specific products and services; 4. Delivering a value proposition to a customer; 5. Providing post-purchase customer support. i3 project will help ICT-19 projects to answer the questions: "Through which channels do our customers segments want to be reached?", "Which ones are the most cost-efficient?"

Customer relationships: provides project with idea which type of relationship they establish with specific customer segments. 3 team will provide projects the evaluation of what types of customer relationships they want to establish and what is the motivation of such relationships: will it be customer acquisition? Customer retention or boosting sales.

Key resources: i3 team will help project to analyse their key resources that allow creating and offering customer segments, reach markets, maintain relationships with customer segments and earn revenue. During providing economic impact assessment projects have to answer next questions: "What key resources do our value propositions requires?", "Our distribution channel?", “Customer relationships?", "Revenue streams?"

Key activities: $\mathrm{i} 3$ will help to evaluate the most important things a project must do to make its business model work. Like key resources, they are required to create and offer a value propulsion, reach market, maintain customer relationships and earn revenue.

Key partnership: helps to identify the network of suppliers and partners that make a business model works. Companies create alliances to optimise their business models, reduce risk, or acquire resources. Projects will have to answer the following questions: "Who are our key partners?", "Who are our key suppliers?", "Which key resources are we acquiring from partners?" 
Cost Structure and Revenue Streams: helps to analyse the cash a project generates from each customer segment and all costs incurred to operate a business model. A project must ask itself, for what value is each customer segment truly willing to pay? Successfully answering that question allows the firm to generate one or more revenue streams from each customer segment. Each revenue stream may have different pricing mechanisms. Cost structure will be analysed by incurring cost from creating and developing value, maintaining customer relationships and generating revenue.

Sustainability: this indicator allows understanding if the projects results can be sustainable in the 3-5 years perspective from the economic point of view.

\section{Social impact}

This area of impact and associated indices consider all social results that projects develop during their lifetime. The SEQUOIA methodology (Passani et al., 2012) provides that social impact is generally divided into following subsections: Social capital; Impact on employment and working routine; Knowledge production and sharing.

Each of the categories is divided into subcategories that can be adapted in relation to the project specifications. At micro level, the aim is to understand changes occurred on the level of individual projects and their users, and - to a certain extent -project partners. At meso level, the aim is to investigate social relations at group and organisational level, such as the impact on Social Media sector.

Moreover, taking into account the IR framework, it was examined the possibility to match IR with the SEQUOIA methodology in relation to the social impact. It was derived that innovator capacity assessment criteria takes into account the innovator's environment. This point quite overlaps with the framework provided by the SEQUOIA methodology. For this reason, the current methodology takes input from IR but enlarges it opening at other research questions always related to the field of investigation, emphasising also points that are not stressed in the IR methodology but that are relevant for i3 impact assessment methodology.

In line with this social impact is composed by the three main categories (social capital, employment and knowledge) further divided in the following sub-categories as summarized in table below.

Table 1. Social Impact Overview

\begin{tabular}{|l|l|l|}
\hline \multicolumn{2}{|l|}{ Social Impact } & a. Impact on contents creation \\
\cline { 3 - 3 } & \multirow{2}{*}{ Social Capital } & b. Impact on community building and engagement \\
\hline 2 & $\begin{array}{l}\text { Employment \& } \\
\text { working routines }\end{array}$ & a. Impact on general employment \\
\cline { 3 - 4 } & b. Impact on working routines \\
\hline 3 & Research and Academia & a. Impact on knowledge production \\
\cline { 3 - 4 } & & b. Impact on knowledge sharing \\
\hline
\end{tabular}

Source: Authors' own processing.

\section{Innovation impact}

This dimension will be explored by collecting, through vertical indicators, the entire set of information needed to build the Innovation Radar (IR). IR methodology includes two 
components: the first is the assessment framework for ranking innovations and the second is an assessment framework for ranking of innovators.

In order to provide synthetic comparable results for further analysis and interpretation, the innovation potential assessment framework uses three assessment criteria: Market Potential (MPI - Market Potential Indicator), Innovation Readiness (IRI Innovation Readiness Indicator) and Innovation Management (IMI - Innovation Management Indicator.

In order to create an Innovator capacity assessment indicator, we proceed in two steps. In a first step, composite sub-indicators are created, one for each of the above defined criteria: Innovator's Ability and Innovator's Environment. This way, two intermediate subindicators are used in order to assess each innovation dimension, i.e.:

Innovator's Ability Indicator (IAI) is an arithmetic aggregate of all relevant information in the domain of innovator's ability

Innovator's Environment Indicator (IEI) is an arithmetic aggregate of all relevant information in the domain of innovator's environment as defined in Section 3.

In the second step, the Innovator Capacity Indicator (ICI) is constructed. The ICI is an arithmetic composite indicator aggregating the values of the two earlier sub-indicators, i.e. IAI and IEI. Like in the case of innovation ranking, equal weighting is applied.

\section{Self-Assessment Toolkit (SAT)}

The SAT allows the acquisition of project's information. It has been structured to guide the users in gathering the information with simple wizard (a guided procedure). The i3 team designed and developed the tool by dedicating particular attention to user experience in order to make the tool as simple and intuitive as possible.

In order to access the dedicated online tool for data gathering, projects coordinators received a username and a password, then entered the information needed and, thirdly, were able to ask to specific partners (one or more) to fill-in specific sections.

The first sections are the focal point of the tool: they enable and give shape to all the other sections. In the first session, the user has to provide basic information about the project (project budget, start date, end date, previous experience in the Convergence and Social Media domain, information about the consortium, etc.), its stakeholders and the expected outputs. 


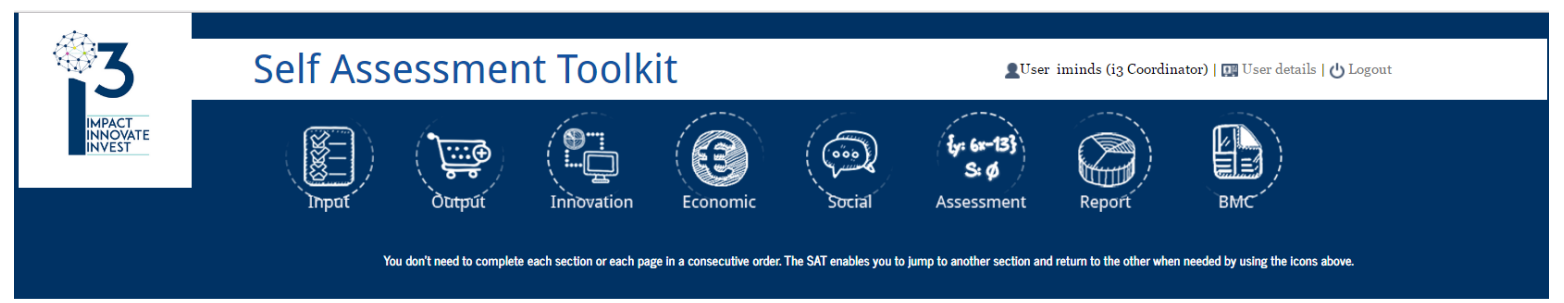

PICBE | 990

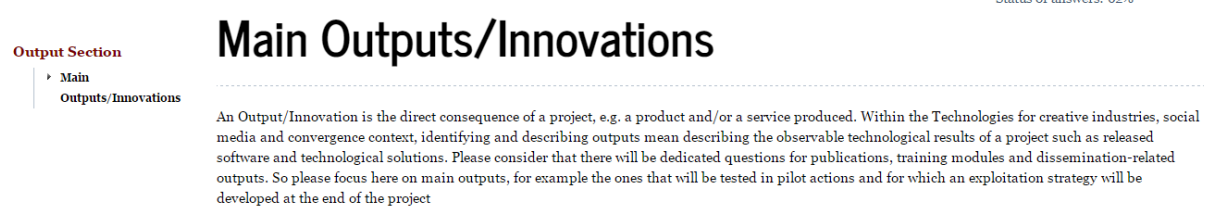

Q1. Which are the innovative technological outputs of your project? Please list a max of 3 and describe

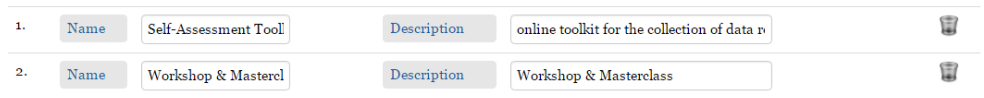

Add Ro

Figure 3. i3 SAT outputs definition

Source: Authors' own illustration.

The users can modify the information filled in these sections at any time by adding or removing output, changing therefore the results of his assessment. The central sections of the tool gather information about specific outcomes and impact showing quantitative closed questions, Likert scales and qualitative open questions.

The last section of the tool shows the result of the impact assessment, i.e. the expected impact of the project under analysis.

\section{Your Assessment Result performed on 2017-01-10 \\ 14:24:02}

Total

48

GooD

Your score: $48 \%$

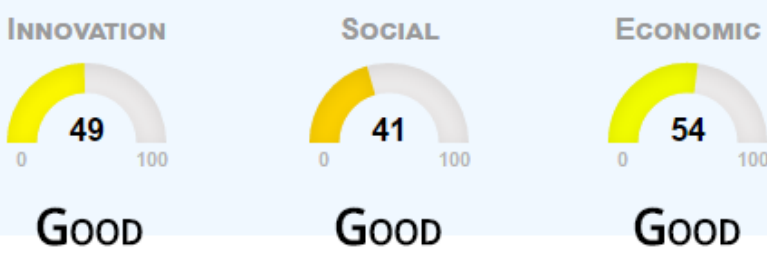

Figure 4. i3 SAT aggregated assessment

Source: Authors' own illustration. 


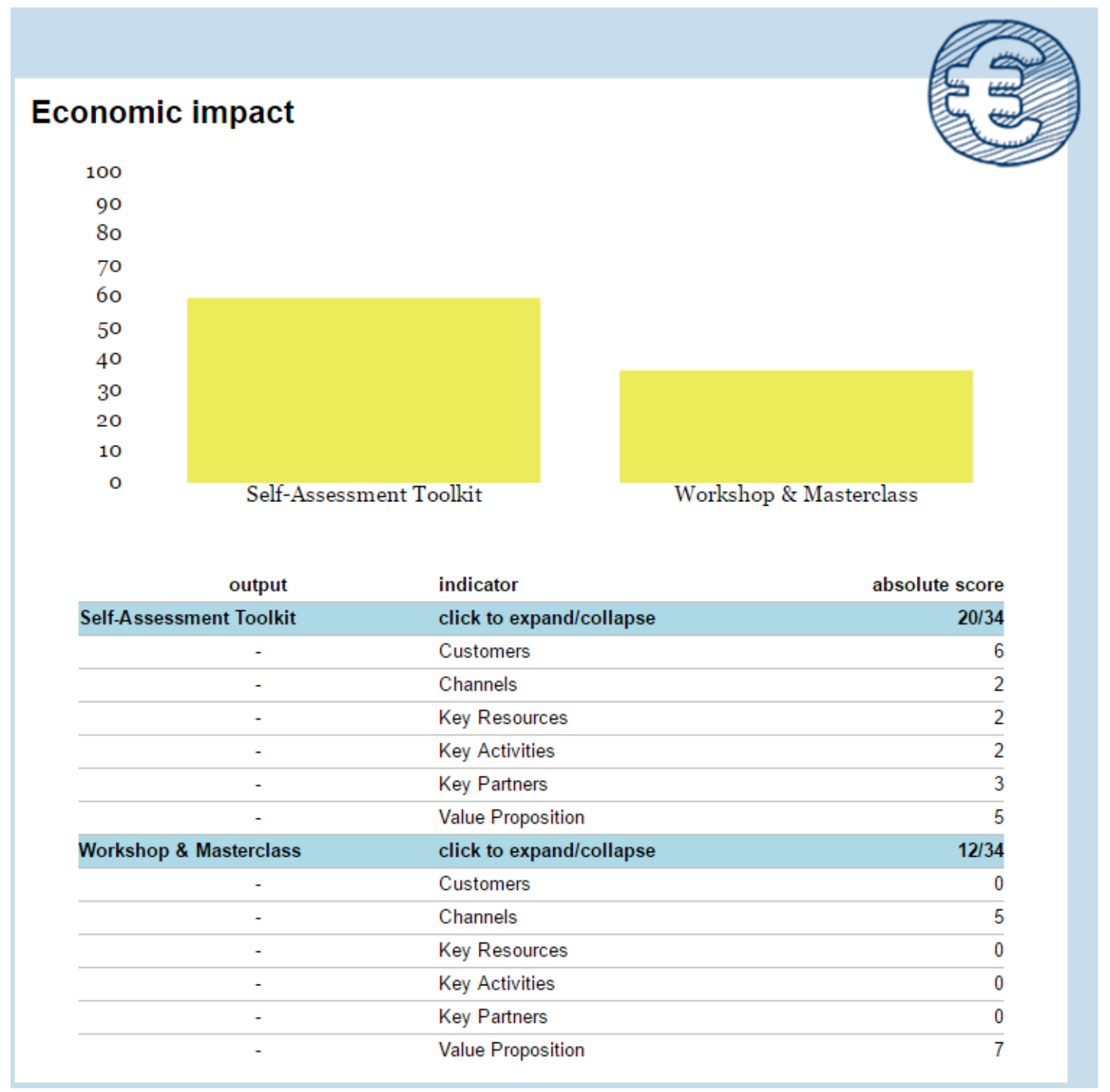

PICBE | 991

Figure 5. i3 SAT assessment detail

\section{Business Model Canvas per Output}

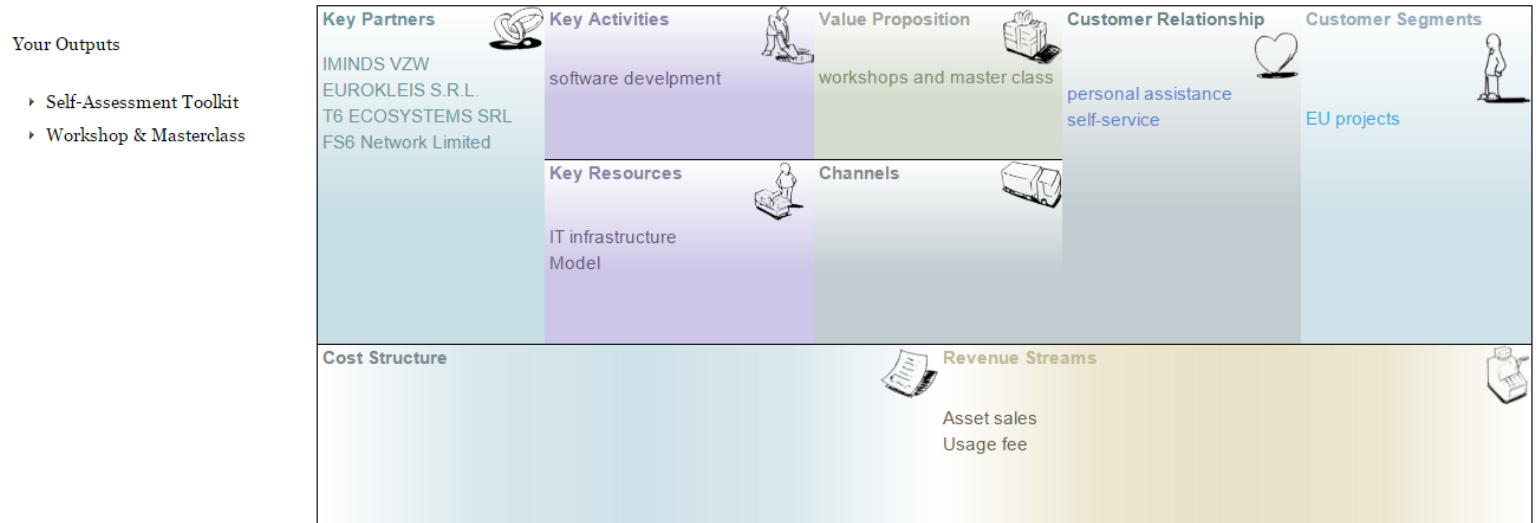

Figure 6. i3 SAT business model designer

Source: Authors' own illustration. 


\section{Conclusions}

The methodology and tool presented in this paper were already presented and discussed with the Social Media and Convergence projects and outside this technological domain. The SAT is perceived as a useful instrument in order to first evaluate if the innovation can be deployed in a successful business (i.e. startup, spinoff).

The methodology and the tools will be updated according to the feedback received

PICBE | 992 and to the analysis of the collected data.

These results will be counter validated through the meeting with investor $\mathrm{s}$ and venture capitalist that will have the occasion to compare the i3 analysis to their personal opinion on projects results.

\section{References}

Bellini F., Monacciani, F., Navarra, M., Passani, A. (2012). Socio-economic impact assessment of research e-Infrastructures: a proposal for a methodological approach. In: Paul and Miriam Cunningham (Eds). INFORMATION AND COMMUNICATION TECHNOLOGIES AND THE KNOWLEDGE ECONOMY. Dublin: IIMC International Information Management Corporation, ISBN/ISSN: 9781905824359

Bellini, F., Passani, A., Spagnoli, F., Crombie, D., \& Ioannidis, G. (2014). MAXICULTURE: Assessing the Impact of EU Projects in the Digital Cultural Heritage Domain. In Digital Heritage. Progress in Cultural Heritage: Documentation, Preservation, and Protection (pp. 364-373) - LECTURE NOTES IN COMPUTER SCIENCE Vol 8740 Springer International Publishing ISBN: 978-3-319-13694-3

De Prato, G., Nepelski, D., \& Piroli, G. (2015). Innovation radar: identifying innovations and innovators with high potential in ICT FP7, CIP \& H2020 projects. Science and Policy Report, Joint Research Centre.

Ebrahim, A.S., Rangan, V.K., (2010). The limits of nonprofit impact: a contingency framework for measuring social performance, Harvard Business School General Management $\begin{array}{llll}\text { Unit } & \text { Working } & \text { Paper } & \text { 10-099 }\end{array}$ http://www.hbs.edu/faculty/Publication\%20Files/10-099.pdf

Epstein, M.J., McFarlan, F.W. (2011). Measuring the efficiency and effectiveness of a nonprofit's

performance, Strategic Finance, 93/4, http://www.imanet.org/PDFs/Public/SF/2011_10/10_2011_epstein.pdf

Jenkins, H. (2006). Convergence Culture: Where Old and New Media Collide, New York: New York University Press.

Mendoza and Macoun (1999), Guidelines for Applying Multi-Criteria Analysis to the Assessment of Criteria and Indicators. Center for International Forestry Research (CIFOR).

Mendoza and Martin (2006), Multi-criteria decision analysis in natural resources management: A critical review of methods and new modeling paradigms, Forest Ecology and Management, 230, pp. 1-22.

Osterwalder, A., \& Pigneur, Y. (2010). Business model generation: a handbook for visionaries, game changers, and challengers. John Wiley \& Sons

Passani A., Monacciani F., Van Der Graaf S., Spagnoli F., Bellini F., Debicki M., Dini P. (2014). SEQUOIA: A methodology for the socio-economic impact assessment of Software-as-a- 
Service and Internet of Services research projects. RESEARCH EVALUATION; ISSN: 0958-2029

Passani, A., Spagnoli, F., Bellini, F., Prampolini, A., \& Firus, K. (2016). Collective Awareness Platform for Sustainability and Social Innovation (CAPS). In Organizational Innovation and Change (pp. 103-114) - LECTURE NOTES IN INFORMATION SYSTEMS AND ORGANISATION (LNISO) Vol. 13. Springer International Publishing.

Uricchio, W. (2004). Beyond the Great Divide: Collaborative networks and the challenge to dominant conceptions of creative industries. International Journal of Cultural Studies, 7(1), 79-90. 